\title{
Adesão medicamentosa em pacientes com múltiplas doenças crônicas: um estudo de prevalência em ambulatório de medicina interna de hospital terciário
}

\author{
Borges, F.K.; Londero, T.M.; Oliveira, F.S.; Reznicek, L.; Siqueira, P.Z.; \\ Furlanetto, T.W.;
}

Apresentador: Flávia Kessler Borges

\section{Resumo}

Introdução: É freqüente a associação de vários medicamentos para controlar doenças em pacientes crônicos. Contudo, a adesão medicamentosa é variável e os fatores associados diferem, não havendo dados uniformes sobre o assunto. Metodologia: Estudo transversal em pacientes do ambulatório de Medicina Interna de hospital terciário, maiores de 18 anos com duas ou mais doenças crônicas visando estimar a adesão medicamentosa pela Escala de Adesão Medicamentosa de Morisky. Fatores associados a adesão foram avaliados pela regressão de Poisson. O controle das doenças crônicas foi avaliado e definido como alvos atingidos de hipertensão, diabetes e dislipidemia. Resultados: Um total de 170 pacientes (idade média 65 $\pm 9,8$ anos), 61 homens $(36 \%)$ foram incluídos. Sessenta e sete pacientes possuíam até 4 anos de estudo renda menor que mil reais foi referida por 56 pacientes. O número médio de comorbidades foi $4 \pm 1,14$, sendo HAS a doença mais prevalente (96,5\%), seguido de DM2 (67\%). Cada paciente usava 7,5 $\pm 2,5$ medicamentos. A taxa de controle das doenças crônicas mais prevalentes foi: HAS 72\% (IC95\% 65-79\%), DM 53\% (IC95\% 42-63\%) e dislipidemia 51\% (IC95\% 41-61\%). A prevalência de média e alta adesão foi $43 \%$. Os fatores que se associaram independentemente à adesão medicamentosa foram prática de exercício físico RP 1,63 (IC 95\% 1,09-2,44 p = 0,017) e idade RP 1,02 (IC 95\% 1,00-1,03 p=0,032). Conclusão: Menos da metade dos pacientes do ambulatório de Medicina Interna adere à prescrição médica. É necessário instituir novas estratégias para que os pacientes se beneficiem das prescrições de medicamentos.

\section{Referência:}

Borges, F.K.; Londero, T.M.; Oliveira, F.S.; Reznicek, L.; Siqueira, P.Z.; Furlanetto, T.W.;. Adesão medicamentosa em pacientes com múltiplas doenças crônicas: um estudo de prevalência em ambulatório de medicina interna de hospital terciário. In: II Congresso Brasileiro de Medicina Hospitalar - II CBMH [= Blucher Medical Proceedings, vol.1, num.5] São Paulo: Editora Blucher, 2014. p.85

DOI 10.5151/medpro-II-cbmh-083 